HRALTH OF SCOTCH TOWNS.

The annual rate of mortality in the eight Scotch towns, which had been 18.8 and 19.5 per 1000 in the preceding two weeks, further rose to 20.9 in the week ending July 23rd; this rate, however, was 1.3 below the mean rate during the same week in the twenty-eight large English towns. The rates in the Scotch towns last week ranged from $18 \cdot 7$ and $19 \cdot 1$ in Edinburgh and Aberdeen, to 23.1 in Paisley and 23.7 in Dundee. The 523 deaths in the eight towns last week showed a further increase of 36 upon the numbers in the preceding two weeks, and included 39 which were referred to diarrhoea, 37 to whooping-cough, 9 to "fever" (typhus, enteric, or simple), 8 to diphtheria, 5 to scarlet fever, 5 to measles, and not one to small-pox; in all, 103 deaths resulted from these principal zymotic diseases, against 84 and 93 in the preceding two weeks. These 103 deaths were equal to an annual rate of $4 \cdot 1$ per 1000 , which was $2 \cdot 6$ below the mean rate from the same diseases in the twenty-eight English towns. The fatal cases of diarrhoe, which had increased in the previous four weeks from 10 to 30 , further rose last week to 39 , of which 16 occurred in Glasgow, 6 in Dundee, and 6 in Paisley. The deaths from whooping-cough, which had been 46 and 43 in the preceding two weeks, further declined last week to 37 , and included 14 in Edinburgh, 10 in Glasgow, and 5 in Dundee. The 9 deaths referred to "fever" showed an increase upon the low numbers returned in recent weeks; 5 occurred in Glasgow, 2 in Edinburgh, -1 in Aberdeen, and 1 in Leith. The fatal cases of diphtheria were also more numerous, and included 2 in Edinburgh and 2 in Leith. The 5 deaths from scarlet fever were fewer than in any recent week; 4 were returned in Dundee. Three of the 5 deaths from measles occurred in Glasgow. The deaths referred to acute diseases of the respiratory organs in the eight towns, which had been 80,76 , and 65 in the previous three weeks, rose again last week to 77 , and were 10 above the number returned in the corresponding week of last year. The causes of 74 , or more than 14 per cent., of the deaths registered in the eight cowns during the week were not certified.

HEALTH OF DUBLIN.

The rate of mortality in Dublin, which had been 26.6 and 27.9 per 1000 in tha preceding two weeks, further rose to 29.9 in the week ending July $23 \mathrm{rd}$. During the first three weeks of the current quarter the death-rate in the city averaged 28.1 per 1000 , the mean rate during the same period being but 22.1 in London and $19 \cdot 1$ in Edinburgh. The 202 deaths in Dublin last week showed a further increase of 13 upon the numbers returned in the previous two weeks; they included 21 which were referred to measles, 21 to diarrhoea, 3 to whooping-cough, 2 to "fever" (typhus, enteric, or simple), 1 to scarlet fever, and not one either to smallpox or diphtheria. Thus the deaths resulting from these principal zymotic diseases, which had been 47 and 45 in the preceding two wreks, rose last week to 48 , and exceeded the number returned in any previous week of this year; they were equal to an annual rate of $7 \cdot 1$ per 1000 , the rates from the same diseases being 85 in London and 4.2 in Edinburgh, The fatal cases of measles, which had been 36 and 28 in the previous two weeks, further declined last week to 21. The deaths attributed to diarrhœe, on the other hand, rose to 21 , from 3 and 12 in the preceding two weeks. The deaths from the other zymotic diseases did not materially differ from the numbers in recent weeks. The deaths of infants exceeded the number returned in any previous week of this year, and the deaths of elderly persons also showed a marked increase. T'wo inquest cases and 2 deaths from violence were registered; and 49 , or nearly a quarter, of the deaths occurred in public institutions. The causes of 27 , or more that 13 per cent., of the deaths registered during the week were not certified.

\section{THE SERVICES.}

ADMIRALTY.-In accordance with the provisions of Her Majesty's Order in Council of April 1st, 1881, Staff Surgeon Cecil Drake has been placed on the retired list of his rank (dated July 12th, 1887).

The following appointment has been made:-Surgeon James A. Vesey, to the President, for temporary service (dated August 2nd, 1887).

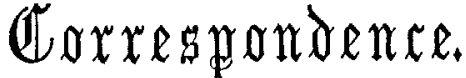

"Audi alteram partem."

DISEASE AND MEDICAL ATTENDANCE IN WORKIIOUSES.

To the Editors of THE LANCET.

SIRs,-A leader in last week's LANCET refers to an inquest held on the body of a patient, who died in the infirmary, St. George's-in-the-East, and, as one or two points in the account of the inquest require further el ucidation, I trust you will grant me space for that purpose, and also to comment briefly on the article.

After the patient was admitted to the workhouse, she was warded amongst the aged and infirm, and the ward she occupied was under the supervision of a paid nurse both by day and night. During the night she got out of bed and fell near the fireplace, with her left arm on the fender. Of course there was no fire in the grate. The patient did not appear to be injured by the fall, and after being put back in bed another inmate sat by her side, and the nurse visited the ward from time to time as usual. In the morning when I saw her, she was quite able to walk about, and did not think anything of the injury, which was simply a bruise of the left arm, and not one private patient in a thousand would have called a medical man in the night to see it. As her mind was becoming affected she was removed to the infirmary, when an attack of acute senile mania supervened, and she died. During her residence in the infirmary she was seen at least twice daily by the medical officer or myself, and the former left the infirmary only two days before she died. The relative who called to inquire after her on the Monday was not allowed to see her, as I did not think it desirable for him to do so in the state of mind she was then in, and she had been visited by friends on the previous day. He, however, put too hopeful a construction on my words when he stated that I said she would be all right in a few days

I do not see that this case affords an illustration of any want of care or attention. Had she been injured by the fall a message would have been sent immediately to the medical officer.

I will now turn to the question of additional medical advice for the inmates of Poor-law institutions, and, at the very outset, beg to express my opinion that the inmates of these institutions receive far more medical aid than most people do at their own homes, and who pay for it. You allow that we are capable men and incapable of any unkindness, but at the same time you think that another opinion might be provided by some means or another. Respecting our capabilities, I think I may say, and without fear of being considered guilty of boasting, that we are quite equal to the average medical man. For Poor-law appointments there is no lack of good candidates, and usually, though perhaps not always, the best are elected. As regards the advisability of providing further medical advice for the recipients of parochial relief, I must say that I think it a question open for discussion. I should be very sorry to stand in the way of anyone from receiving the best medical or surgical advice in a serious illness. It might be argued, and argued with very great force, that medical officers of Poor-law institutions are men of very considerable professional attainments, and fully capable of treating all cases that come under their charge. Again, in London many of the patients in workhouse infirmaries have previously derived all the benefit they can from treatment at hospitals; and should any patient require operative treatment the medical officer does not care to undertake, ho can transfer the case to a hospital. Of course, consultants might be appointed, whose advice and assistance should be available when required, and for which they should receive appropriate remuneration. It would never do to allow inmates and their friends to call in medical men when they wished; such a system would upset the working of any institution, and assuredly a medical officer's berth is not such a bed of roses that anyoue would wish to make it more unpleasant. We certainly might have some additional help, and I believe it would be found to answer best if given by the appointment of more junior officers. Such assistance would be an advantage to both medical officers and patients, and would 
be a means of gaining experience in fields of practice particularly useful to recently qualified medical men.

During the past fifteen years or so great strides have been made in medicine and surgery, but I believe in no departments have there been more improvements than in the medical administration of our Poor-law institutions.

I am, Sirs, yours faithfully,

$$
\text { July 26th, 1887. ARTHUR FflintoFF MickLe, M.B. }
$$

\section{"SUBSTANTIVE VERSUS HONORARY RANK."}

To the Editors of Thes LANCET.

SIRs,- So many sensible letters, supported by your favourable comments, have appeared in THE LANCET against honorary rank for medical officers in the army, that nothing more seemed necessary to be said. Having, however, just heard from a friend that a medical contemporary supports the idea of honorary rank, and teems with letters in favour of it, I venture to suggest that the wishes of the majority of medical officers are not represented by these letters. Naturally, those wanting honorary rank write; while the contented ones remain, as a rule, quiet. But there is, I believe, no doubt that, if there were any danger of honorary rank being given to us, a large majority of the medical staff and of the Indian Medical Service would support Mr. Stanhope's statement in the House of Commons, that they had no wish for "titles so dissociated from the duties of their honourable profession," and would protest in the words of your correspondent, "Army Surgeon," against becoming "the laughing stock of the army."

I am, Sirs, yours faithfully,

S. L. DoBIe,

Kamptee, India, July 3rd, 1887 Surgeon-Major, 4th Madras Cavalry.

\section{VAGINAL HYSTERECTOMY.}

To the Editors of THE LANCET.

SIns,-Dr. Braithwaite's interesting paper in your issue of July 23 rd contains much controversial matter. I would first congratulate him on his success, and then, briefly as possible, touch on certain of his statements as regards the best method of operating. Not having a copy of THE LANCET before me at the time of writing, I must rely on my memory, which I trust will be found accurate.

Dr. Braithwaite disapproves of the use of instruments for checking hæmorrhage from the vessels in the broad ligament, and deprecates any attempt to secure them without retroverting the uterus. My experience is quite opposed to this, and having operated on two cases, and seen a few others done, I have no hesitation in saying that with the use of properlyshaped strong forcipressure forceps with a firm catch the operation is materially shortened and bleeding quite safely controlled. In my cases the body and fundus were large, hence the broad ligaments were of a greater vertical depth, and my forceps would only clamp their lower two-thirds; but when the body is of the normal size the forceps act admirably, and the operation is less difficult. With these instruments there is no fear of any slipping of ligatures or risk of secondary hæmorrhage from their ulcerating through the coats of the vessels. Dr. Braithwaite disapproves of the use of sponges. I can only say that in my last case, which made an admirable recovery, and which was a case of cervical cancer complicated with pregnancy, I found that a soft flat sponge, folded, with a strong carbolised silk ligature tied round its middle and introduced into Douglas's cavity, was an excellent means of absorbing the blood which came from the uterine side after separating the uterus. When removed at the end of the operation, it brings the peritoneal and mucous surfaces outwards and into contact, and they soon unite; hence, in my view, as in that of many others, there is no need for suturing these surfaces. A large drainage tube with capacious holes should be inserted for a couple of days, and syringing commenced at the end of twenty-four hours, and done at least three times daily or of tener according to the amount and condition of discharge. This is very important. Dr. Braithwaite seems to contradict himself with reference to the propriety of first removing the diseased cervix. Unless the mass be large there is no need for this, as the peritoneum need not be infected in the operation with forceps, but in retro- or ante-version with ligature it may be. There are other points in the operation which I must leave to another occasion, but I feel sure Dr. Braithwaite will agree with me when 1 say that in the interest of patients I wish he had insisted that no one should attempt the operation without having practised it on the cadaver a fev times, and without having seen it done on the living.

With regard to the indications for the operation, its mortality, and its comparison with supra-vaginal excision of the cervix, I am compelled by the most recent information to differ from him and other writers on the subject. On the matter of so-called recurrence, which really means an incomplete operation, we must all wait for time to decide as regards total extirpation; but as Schroeder's cervical excision is at best but a partial operation, and has a mortality of at the best 7 per cent, and an all-round mortality several points higher, and as recurrences have been too frequent, I think every careful surgeon would agree that the mortality is far too high for any partial proceeding, and the recurrence is what he would expect. Now, the most recent mortality results of the complete operation are nil-i.e., that two operators have had a series of fifteen or twenty cases without a death,--and I see no reason why experienced operators should not obtain similar results in this country; but even if the expert and all-round mortality were, with recent improved modes of operating, equal to the best results of Schroeder's operation, i should elect the complete operation, as in properly previously examined cases and those proper for the method there is far greater prospect of a permanent cure by the radieal plan. To take the pathology of Ruge and Veit (which is some years old, and needs confirmation) as a basis on which to select an operation can only lead to disappointment, for we hardly ever see cases early enough to feel at all sure that we can get well above the disease; and even if it were proved to demonstration that cancer of the vaginal portion always spreads outwards to the lymphatics in the broad ligament, and rarely, or never, upwards along the canal, I hold that the complete operation would enable us to well remove the diseased parte of the broad ligaments in eaces which are not too far advanced for any operation. In those extremely rare cases which are seen early enough for Schroeder's operation, there can be no comparison between it and the complete one, for these rare cases are suitable for the former and not for the latter; but in the majority of cases, as we first see them, Schroeder's operation, with its high mortality and frequent recurrence (through incompleteness) is, in my opinion, out of court. The ordinary amputation of the cervix by the écraseur and other means is only admissible in cases of papilloma, and even these have been known to return. So that in dealing with ordinary cases of cancer as we see them, whether of the vaginal portion, cervical canal, or body, it seems to me that elytro-hysterectomy is the best proceeding. - I am, Sirs, yours truly, -Grosvenor-street, w., July, 1887.

II. A. REEVES

\section{THE THERAPEUTICAL SOCIETY.}

\section{To the Editors of THe LaNCET.}

SIRs,-At a meeting held last Friday by the kind permission of Dr. Milner Fothergill at his house, the following gentlemen were elected as Executive Council of the above Society, with power to add to their number:-Dr. Milnep Fothergill, M.R.C.P.L.; Mr. Haward, F.R.C.S. Eng.; Dr, Stretch Dowse, F.R.C.P.E. ; Dr. Prosser James, M.R.C.P.L. ; Dr Saundby, F.R.C.P.L.; Dr. Campbell ; and Dr. Illingworth.

A discussion arose, after the reading of a paper on the advantages of this Society, as to the admission as members of all registered general practitioners; and it was finally decided that, as the basis of the Society was to be distinctly "unsectarianism," the following should be the rule for eligibility for admission : "That all qualified medical practitioners shall be eligible for membership provided that they have not already avowedly pledged themselves to any exclusive line of therapeutics." If all gentlemen, therefore, who have already sent in their names for membership, who cannot agree to this rule, will kindly write me a card withdrawing from the Society, [ shall be much obliged; at the same time I trust that they will be "few and far between." It was felt by the Council that as an "unsectarian" Society it would be destructive to admit as members any holding strongly biased views with regard to therapeutics. This Society is founded for "investigation of all methods of medical treatment now existing, or which may afterwards be introduced," and therefore it stands as a reasonable pro- 